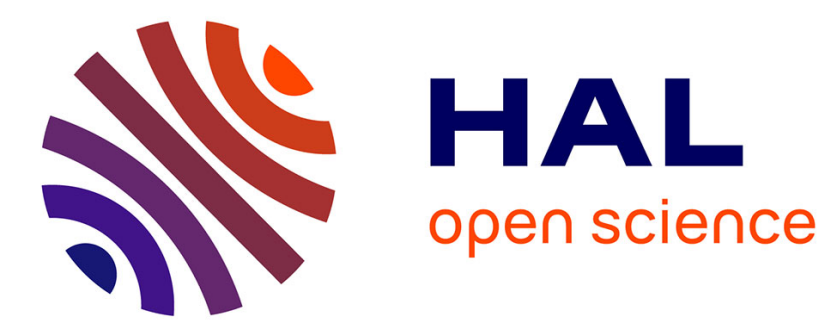

\title{
Positron Annihilation Studies of VVER Type Reactor Steels
}

\author{
G. Brauer
}

\section{To cite this version:}

G. Brauer. Positron Annihilation Studies of VVER Type Reactor Steels. Journal de Physique IV Proceedings, 1995, 05 (C1), pp.C1-143-C1-150. 10.1051/jp4:1995116 . jpa-00253552

\section{HAL Id: jpa-00253552 https://hal.science/jpa-00253552}

Submitted on 1 Jan 1995

HAL is a multi-disciplinary open access archive for the deposit and dissemination of scientific research documents, whether they are published or not. The documents may come from teaching and research institutions in France or abroad, or from public or private research centers.
L'archive ouverte pluridisciplinaire HAL, est destinée au dépôt et à la diffusion de documents scientifiques de niveau recherche, publiés ou non, émanant des établissements d'enseignement et de recherche français ou étrangers, des laboratoires publics ou privés. 


\title{
Positron Annihilation Studies of VVER Type Reactor Steels
}

G. Brauer

Positron Group of TU Dresden at Research Centre Rossendorf, Inc., P.O. Box 510119, D-01314 Dresden, Germany

\begin{abstract}
A summary of recent positron annihilation work on Russian VVER type reactor steels is presented. Thereby, special attention is paid to the out line of basic processes that might help to understand the positron behaviour in this class of industrial material. The idea of positron trapping by irradiationinduced precipitates, which are probably carbides, is discussed in detail.
\end{abstract}

\section{Introduction}

Neutron embrittlement of reactor pressure vesse? (RPV) steels is a.limiting factor in the lifetime of vessels of today's nuclear power plant reactors. Up to now, the underlying mechanisms of irradiation damage have not been completely understood $/ 1$, 2/. However, it seems to be generally accepted now that the presence of cu impurities most strongly influences the irradiation behaviour of RPV steels. It is also clear that irradiation induced precipitates play a dominant role, but pure cu precipitates are definitely not formed $/ 2-5 /$. Therefore a lot of effort is undertaken worldwide to identify the properties and chemical composition of such irradiation-induced precipitates, which finally could lead to a more general understanding of neutron embrittiement.

Several microscopic experimental methods have been employed to investigate neutron embrittlement processes, mostly small angle neutron scattering (SANS), atom probe field ion microscopy (APFIM), and transmission electron microscopy (TEM) - for reviews see refs. $/ 2,6 /$.

With the development of commercially available positron sources, such as $22 \mathrm{Na}$, positron annihilation spectroscopy (PAS) techniques are being increasingly employed in many fields of technical interest among those are radiation damage in RPV steels $/ 7-10 /$ and fusion reactor materials $/ 11 /$.

\section{Physical background}

Characteristics of materials such as strength and toughness are mainiy caused by the microstructure of the material. Therefore, generally the microstructural constituents essential for the fracture process are the particles present in the matrix, like inciusions and precipitates. Radiation damage can result in extreme changes of the mechanical properties of a material and therefore its identification and characterization is of main importance. 
PAS is a powerful tool for the investigation of defects with the electron density less than average, vacancies and vacancy clusters (voids) in particular, and can give also useful information about precipitates $/ 12,13 \%$. From the study of metals it is known, that monovacancies are detected within a concentration range of $0.1-200$ $\mathrm{ppm}$, dislocations within $10^{12}-10^{15} \mathrm{~m}=2$, and voids (diameter $4.5 \mathrm{~nm}$ ) already from $2 \times 10^{-8}$ per atom. Voids in metals can be detected by positrons up to a size that corresponds to the agglomeration of about 50 monovacancies. This shows, that by PAS the study of microstructural defects is possible which are not longer detected by TEM. Interstitial atoms and stacking faults are not seen by positrons. For certain types of impurity atoms it is experimentally possible to distinguish free monovacancies from vacancies bound to impurity atoms.

Positrons practically do not interact with single impurity atoms in a matrix, whereas already sma?l clusters of impurity atoms might be attractive to positrons. However, only few experimental and theoretical positron studies regarding the clustering of solute atoms in alloys are known up to now (see e.g. refs. $/ 14,15 /$ and references therein). Positrons can be trapped by precipitates if these have a positron affinity $A_{+}$lower than the bulk material where they are embedded, and if the precipitates are larger than a certain critical size /15/.

The knowledge of positron affinities of the matrix and the precipitates heips to understand positron trapping in alloys. This was demonstrated for the first time in ref. $/ 15 /$ for $\mathrm{Zn}$ precipitates in the Al matrix. A positron $w i 11$ be trapped by a precipitate if the difference $\Delta A_{+}$of the positron affinities of the host and the precipitate is positive and the radius of the precipitate exceeds the critical radius $r_{0}$ given by $/ 15 /$ :

$$
r_{C}=0.31 /\left(A A_{+}\right)^{1 / 2}
$$

Here $A_{+}$is giver in $e V$ and $r_{c}$ is obtained in $n m$ (a spherical shape of the precipitates is assumed). In case of pure $\mathrm{Zn}$ precipitates in the $A 1$ lattice, the critical radius of precipitates amounts to $0.34 \mathrm{~nm}$, i.e. the precipitates should contain at least $11 \mathrm{Zn}$ atoms in order to trap a positron. In Tab.1 calculated positron affinities /15/ for several elements from the Periodic Table are presented. possibilities for a direct experimental verification of affinity calculations have been reported recentiy $/ 16 /$.

TABLE 1

Positron affinity $A_{+} /$eV/ for different elements of the Periodic Table

\begin{tabular}{|c|c|c|c|c|c|c|c|c|c|c|c|c|c|}
\hline \multirow{2}{*}{ 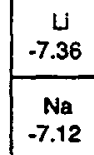 } & \multirow{2}{*}{$\frac{\begin{array}{c}B \theta \\
-3.11\end{array}}{\begin{array}{c}M g \\
-6.18\end{array}}$} & & & & & & & & & & & \multirow[b]{2}{*}{$\begin{array}{c}A l \\
4.41\end{array}$} & \multirow[b]{2}{*}{$\begin{array}{c}\mathrm{Si} \\
-6.95\end{array}$} \\
\hline & & & & & & & & & & & & & \\
\hline $\begin{array}{c}K \\
-7.05\end{array}$ & $\begin{array}{c}\mathrm{Ca} \\
-6.40\end{array}$ & $\begin{array}{c}\text { Se } \\
-5.10\end{array}$ & $\begin{array}{c}\pi \\
-4.06\end{array}$ & $\begin{array}{c}V \\
-3.44\end{array}$ & $\begin{array}{c}C r \\
-2.62\end{array}$ & $\begin{array}{c}\mathrm{Mn} \\
-3.72\end{array}$ & $\begin{array}{c}F_{0} \\
-3.84\end{array}$ & $\begin{array}{c}c 0 \\
-4.18\end{array}$ & $\begin{array}{r}\mathrm{Ni} \\
-4.46\end{array}$ & $\begin{array}{r}\text { Cu } \\
-4.81\end{array}$ & $\begin{array}{c}Z n \\
-5.24\end{array}$ & & $\begin{array}{c}G_{\theta} \\
-6.69\end{array}$ \\
\hline $\begin{array}{c}R b \\
-6.98\end{array}$ & $\begin{array}{c}S t \\
-6.41\end{array}$ & $\begin{array}{c}Y \\
-5.31\end{array}$ & $\begin{array}{c}27 \\
-3.98\end{array}$ & $\begin{array}{c}\text { Nb } \\
-2.93\end{array}$ & $\begin{array}{c}\text { Mo } \\
-1.82\end{array}$ & $\begin{array}{c}\text { To } \\
-1.67\end{array}$ & $\begin{array}{c}R u \\
-1.92\end{array}$ & $\begin{array}{c}\text { Rh } \\
-3.10\end{array}$ & $\begin{array}{c}\mathrm{Pd} \\
-5.04\end{array}$ & $\begin{array}{c}A_{d} \\
-5.36\end{array}$ & $\begin{array}{c}C d \\
-5.78\end{array}$ & & $\begin{array}{r}S n \\
-7.60\end{array}$ \\
\hline $\begin{array}{c}\text { Cs } \\
-6.94\end{array}$ & $\begin{array}{r}\mathrm{Ba} \\
-6.13\end{array}$ & $\begin{array}{c}\text { LU } \\
-4.90\end{array}$ & $\begin{array}{c}\mathrm{HH} \\
-3.70\end{array}$ & $\begin{array}{c}\mathrm{Ta} \\
-2.63\end{array}$ & $\begin{array}{c}W \\
-1.31\end{array}$ & $\begin{array}{c}R e \\
-0.97\end{array}$ & $\begin{array}{c}08 \\
-0.89\end{array}$ & $\begin{array}{c}\text { It } \\
-1.53\end{array}$ & $\begin{array}{c}\text { Pt } \\
-3.63\end{array}$ & $\begin{array}{c}A u \\
-4.59\end{array}$ & & & $\begin{array}{c}\mathrm{Pb} \\
.5 .56\end{array}$ \\
\hline
\end{tabular}

The interaction of positrons with micrcstructural lattice defects can be described in the frame of the trapping model $/ 12,13 /$. According to the simple trapping model 
(rate equation approach /17/) the trapping rate $q$ of positrons into a certain lattice defect, e.g. monovacancies and dislocations, is given by:

$$
q=H N
$$

where $N$ is the volume concentration of the defects and $\mu$ means a constant which depends on the material investigated as well as the type of the defects for this material.

Positron trapping into defects with larger geometrical dimensions, e.g. voids and precipitates, is a diffusion limited process and requires some modification of the trapping rate calculation according to the geometrical shape of the defect $/ 17 /$. The trapping rate $q$ for a given concentration $N$ of defects with capture radius $r$ may be written as:

$$
q=4 \pi r N D_{+}
$$

$D_{+}$means the positron diffusion constant in the corresponding material. For an ever: distribution of trapping centers their mean distance d may be calculated from their concentration $\mathrm{N}$ according to:

$$
N=6\left(\pi d^{3}\right)^{-1}
$$

It should be pointed out, that experimentally observed positron trapping by a certain kind of defect can always be described in the frame of the trapping mode?. However, it is not justified to conclude from a trapping rate, which can be evaluated quite formally for a given distribution of solute atom clusters (which might have been estimated from another method), that this kind of defect, created some way by irradiation, is really able to attract and trap a positron. This can be decided on the basis of the positron affinity $A_{+}$- as a materials property of this soiute atom cluster - only.

In order to be able to calcuiate the positron affinity $A_{+}$of a solute atom cluster as well as measurable positron annihilation characteristics, e.g. the positron iffetime, one has to know the geometrical arrangement (lattice structure) of atoms within the cluster and its configuration in the matrix. Some assumptions about this structure have to be made unless it is not known from other types of experiments. It should be

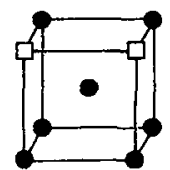

$N=2$

197 ps

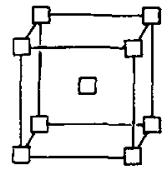

$N=9$

294 pS

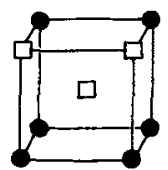

$N=3$

$232 p s$

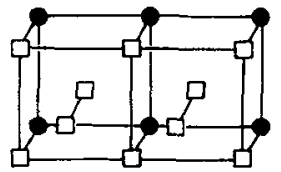

$N=10$

334 ps

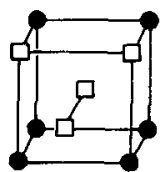

$N=4$

262 ps

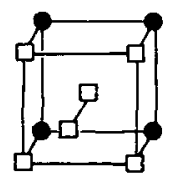

$N=6$

304 ps

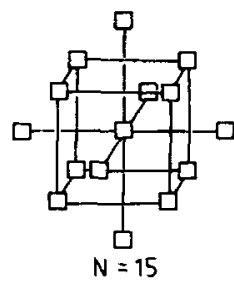

386 ps

Fig. 1 Vacancy agglomerates in bec-structures and corresponding calculated positron lifetime for $\mathrm{Fe} / 18 \% \mathrm{~N}$ - number of vacancies in the agglomerate, a - vacant lattice site. 
mentioned, that in many cases a precipitate (sclute atom cluster) attracts positrons due to the presence of misfit defects (disiocation, vacancies) or more general a strain field around it in the matrix. As mentioned above, a final decision about the trapping of positrons can only be given on the basis of electronic structure calculations resulting in the positron affinity $A_{+}$characterizing this type of defect.

RPV steels may be regarded as an irom matrix containing defects that are able to trap positrons. The typicai positron lifetimes for iron which are agreed now in the international literature to characterize the anninilation in the defect-free bulk, monovacancy, and dislocation are $110 \mathrm{ps}, 175 \mathrm{ps}$, and $165 \mathrm{ps}$, respectively. Typical positron lifetimes for vacanoy agglomerates in iron have been calculated for severa? configurations /18/ and are presented in Fig. 1 .

\section{VVER RPV steels}

RPV steeis of the Russian type 15khaMFA (Cr-tho-V stee s) are used in the VVER-440 type reactors, whereas the Russian type $15 \mathrm{Kh} 2 \mathrm{NMFA}$ (Ni-Cr-Mo-V stee is) is used in the VVER-1000 type reactors. Especially Russian type RPV steels are of great interest to be studied because an understanding of their behaviour under fast neutron irradiation would contribute to an assessment of the safe operation of nuclear power plants in Eastern Europe. Details of standard chemical analyses of VVER type RPV steels are given in Tables 2 and 3 .

TABLE 2

Basic chemical composition of steels for pressure vessels of VVER-440 and VVER-1000 reactors $/ 19 /$

\begin{tabular}{l|l|l|l|l|l|l|l|l|l}
\hline stee 1 type & $\mathrm{C}$ & $\mathrm{Mn}$ & $\mathrm{Si}$ & $\mathrm{P}$ & $\mathrm{s}$ & $\mathrm{Cr}$ & $\mathrm{Ni}$ & $\mathrm{Mo}$ & $\mathrm{V}$ \\
\hline 15Kh2MFA & 0.13 & 0.30 & 0.17 & & & 2.50 & & 0.60 & 0.25 \\
(VVER-440) & to & to & to & $\max$. & $\max$. & to & $\max$. & to & to \\
& 0.18 & 0.60 & 0.37 & 0.025 & 0.025 & 3.00 & 0.40 & 0.80 & 0.35 \\
\hline 15Kh2NMFA & 0.13 & 0.30 & 0.17 & & & 1.3 & 1.0 & 0.50 & \\
(VVER-1000) & to & to & to & $\max$. & $\max$. & to & to & to & $\max$. \\
& 0.18 & 0.60 & 0.37 & 0.020 & 0.020 & 2.3 & 1.5 & 0.70 & 0.10 \\
\hline
\end{tabular}

\section{TABLE 3}

Limit of content of harmful and accompanying elements in steels for pressure vessels /wt $\% / / 19 /$

\begin{tabular}{l|l|l|l|l|l|l|l}
\hline product & $P$ & $S$ & $C u$ & $C o$ & $A s$ & $S b$ & $S n$ \\
\hline pressure vessel & 0.025 & 0.025 & 0.15 & 0.020 & 0.050 & - & - \\
\hline active core & 0.010 & 0.012 & 0.10 & 0.020 & 0.010 & 0.005 & 0.005 \\
\hline
\end{tabular}

Note: The sum of $P+S n+S b$ should not exceed $0.015 \%$.

\subsection{Unirradiated materials}

The unirradiated state of RPV steels type 15Kh2MFA is determined by their production process, i.e. austenitizing at $1000{ }^{\circ} \mathrm{C} / 1 \mathrm{~h} / \mathrm{Ar}$ with $0 i \mathrm{l}$ quenching followed by tempering at $700{ }^{\circ} \mathrm{C} / 10 \mathrm{~h} / \mathrm{Ar}$ with air cooling. Due to this heat treatment a martensitic/bainitic structure is expected.

According to the literature $/ 20 /$ the following microstructural aspects might be important with respect to PAS:

- a dislocation density of the order $5 \times 10^{14} \mathrm{~m}^{-2}$ is expected,

- carbides of the compositions $M_{7} C_{3}, M_{23} C_{6}$, and $M C$ are present (M=meta1).

Regarding the chemical composition, sizes and shapes as well as distributions of 
these carbides the following information is available:

- chromium-rich carbides $\left(M_{7} C_{3}, M_{23} C_{6}\right)$ show two types of morphology, viz. roughly spherical and rod-shaped, with a diameter of about $180 \mathrm{~nm}$ and a planar interparticle spacing of about $1.1 \mu \mathrm{m}$,

- vanadium-rich carbides (MC) have a squared-plate shape with an edge-to-thickness ratio of 15.4. Their nucleation occurs during tempering, where after prolonged tempering treatments their shape changes to roughly spherical. They are at least partially coherent up to $10-15 \mathrm{~nm}$ size. Their distribution is rather even, but grain boundary carbides tend to coarsen preferentially at the expense of the matrix carbides after prolonged tempering. Their mean diameter is about $16 \mathrm{~nm}$ and their conceritration equals about $2200 \mu^{-3}$.

Assuming a carbon content of $0.16 \mathrm{wt} . \%$ it can be found that about $27 \%$ of the carbon is bound within these carbides, whereas the remaining about $73 \%$ of the carbon is bound within the martensitic/bainitic structure $/ 21 /$.

To have an opinion on positron trapping in dislocations and known precipitates according to the production process we have to compare their trapping rate a with the bulk annihilation rate of positrons in pure iron. From eq.(2) we obtain with $\mu_{\mathrm{d}}=1 \times 10^{-4} \mathrm{~m}^{2} \mathrm{~s}^{-1} / 17 /$ for dislocations:

$$
q_{\text {dis }}=5 \cdot \times 10^{10} \mathrm{~s}^{-1}
$$

Assuming the interface between the matrix and a spherical precipitate to trap positrons we can use eqs. (3) and (4) to evaluate the trapping rate $q$ for precipitates. Using $D_{+}=1 \times 10^{-4} \mathrm{~m}^{2} \mathrm{~s}^{-1}$ for iron $/ 12 /$ we obtain for chromium-rich carbides $\left(M_{7} C_{3}, M_{23} C_{6}\right)$ :

$$
q_{c r-c a r b i d e s}=1.6 \times 10^{8} \mathrm{~s}^{-1}
$$

In case of vanadium-rich carbides (MC) we obtain:

$$
2.2 \times 10^{10} \mathrm{~s}^{-1}<\text { av-carbides }<6.6 \times 10^{10} \mathrm{~s}^{-1}
$$

The lower limit results from the assumption of spherical prec pitates with a diameter of $16 \mathrm{~nm}$. The upper 7 imit is to be expected about three times this value because the surface of squared plates with the cited dimensions is about three times larger than that of a sphere with equal volume. The annithilation rate is in the bulk of iron equals:

$$
\lambda_{\mathrm{b}}=\mathrm{x}_{\mathrm{b}}{ }^{-1}=9 \times 10^{9} \mathrm{~s}^{-1}
$$

From a comparison of the trapping rates (5-7) with the bulk annihilation rate (8) can be concluded that in the unirradiated state of these steels chromium-rich carbides $\left(M_{7} C_{3}, M_{23} C_{6}\right)$ represent no significant positron traps. A dislocation density of the cited order would mean more or less saturation trapping if no other defects with Targer trapping cross sections are present. MC carbides seem to represent such traps. The experimentaliy observed annealing behaviour of the unirradiated RPV steels /21/ (a typical curve is shown in Fig. 2) can be explained by a change in their shape from platelike towards sperical up to a temperature of $320-350{ }^{\circ} \mathrm{C}$ thus decreasing the effective number of positron traps. Above this temperature the permanent increase of the mean positron lifetime points to the coarsening of $M C$ carbides thereby again increasing the effective number of positron traps. This conclusion is supported by recent positron affinity calculations for $M C$ carbides $/ 22,23 /$. From these calculations it became furthermore clear that indeed the misfit defects at the particle/matrix interface play the dominant role in the trapping process. 


\subsection{Irradiated materials}

According to combined positron lifetime and Doppler broadening measurements /21/ there is no evidence of the formation of voids, i.e. agglomerates of a certain number of vacancies, in the Russian RPV steels type 15Kh2MFA, if the irradiation takes place above $480 \mathrm{~K}$, the highest temperature found for the break-up of carbon-vacancy pairs in iron $124,25 \%$. Typical isochronal annealing curves are shown in Fig. 2.

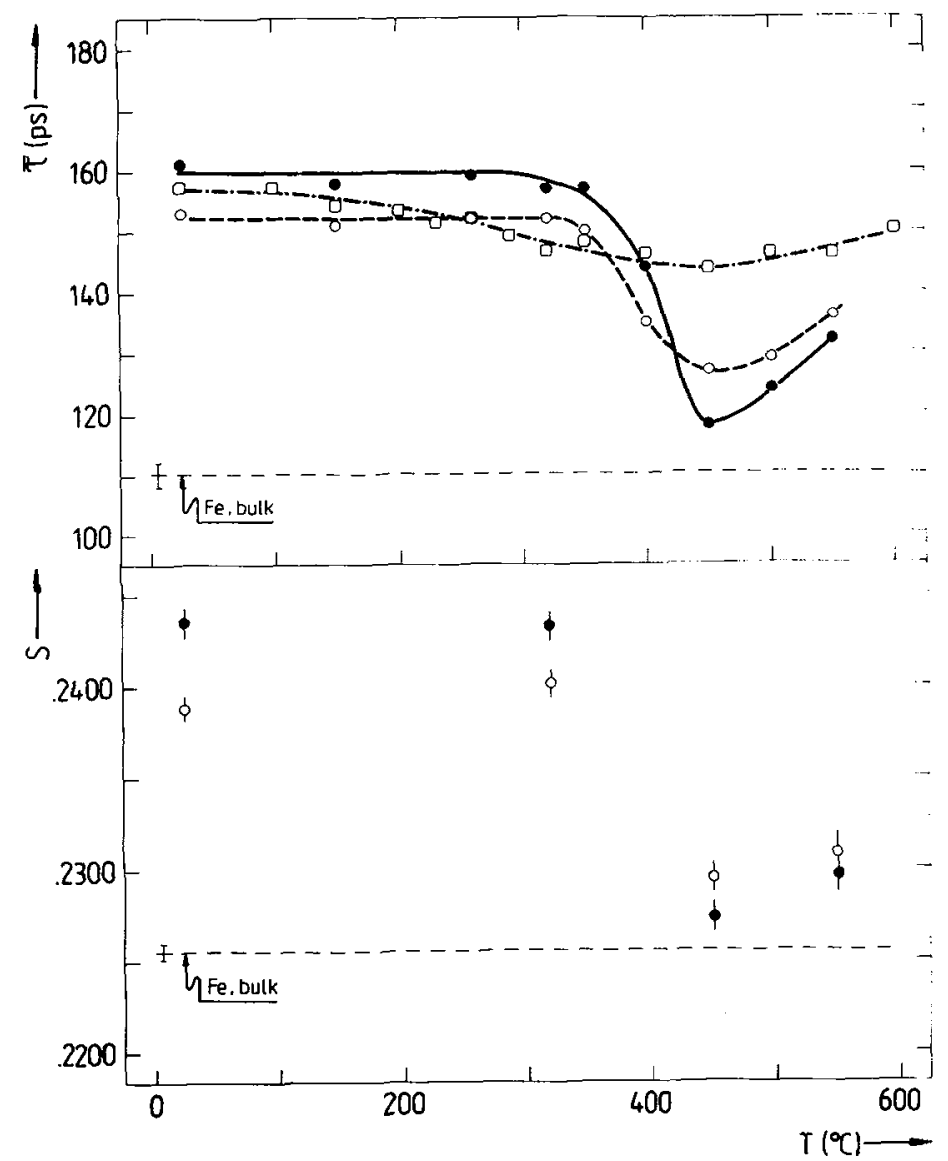

Fig. 2

Mean positron lifetime $\bar{\tau}$ and Doppler broadening parameter $s$ as a function of successive isochronal annealing (30 min) . at different temperatures $T$ for material GGO irradiated at 538 $K$ to different fluences $\Phi / 21 /$ : - - unirradiated - - irradiated $\Phi=3.7 \times 10^{22} \mathrm{~m}^{-2}$ -
$\Phi=7.0 \times 10^{23} \mathrm{~m}^{-2}$

In the literature /28, $27 /$ irradiation-enhanced $\mathrm{Cu}$ precipitates and solute coated microvoids are thought to be major defect types responsible for strengthening and hence embrittling of RPV stee 15 . In contrast to this, from numerous annealing studies on differently irradiated materials $/ 21 /$ here the irradiation-induced precipitates, i.e. probabiy carbides, were suggested to play this role. Similar positron studies of Russian type $15 \mathrm{Kh} 2 \mathrm{NMFA}$ RPV steels resulted in the same conclusions $/ 28 /$.

For the first time, the existence of irradiation-induced defects formed in RPV steels type 15Kh2MFA and 15Kh2NMFA, respectively, was clearly demonstrated by SANS $/ 29 \%$ and a characterisation of these defects was given. The defect structures formed partiy correlate with the chemical composition of the steels. Some more detailed considerations /30/ were presented in order to compare the SANS results /29/ with the suggestions from the positron annihilation results $/ 21,28 /$. It was shown that the idea from positron annihilation, namely the interpretation of the irradiation-induced precipitates as carbides, is neither contradicted nor confirmed by the SANS results. However, it has been shown later /31/ that the volume fraction of these precipitates correlates with the ductile-to-brittle transition temperature of the materials, a very important mechanica? material property. 
An extensive discussion /23/ of the recent positron affinity results /22/ for several carbide, nitride and Cu precipitates in $\mathrm{Fe}$ has shown that such type of theoretjcal work is highly necessary for an improved analysis and understanding of positron annihilation studies of model alloys and RPV steels. In particular, for Fe-Cu alloys it seems that the precipitation of $\mathrm{Cu}$ atoms in the $\mathrm{Fe}$ matrix is not detected by positrons due to the affinity difference between $\mathrm{Fe}$ and $\mathrm{Cu}$ but probably due to the mismatch at the precipitate/matrix interface. By far, regarding the identification of irradiation-induced precipitates in RPV steels the number of possibilities is not exhausted, but already the cases considered point out the importance of the precipitate/matrix interface which should gain more attention in future studies.

A direct estimation of the chemical composition of the irradiation-induced precipitates in the Russian type RPV steels by APFIM is underway and first results could already be presented for the study of unirradiated materials /32/. A paralie? search is performed by anomalous small angle X-ray scattering (ASAXS) and a $f$ irst evaluation of experimental data revealed the presence of vanadium atoms in the irradiation-induced precipitates at a valence state that supports the idea of carbide formation $/ 33 /$.

\section{Summary}

The specifics of PAS to study radiation damage have been out ined and applied to the study of Russian VVER type RPV steels. From these studies the formation of irradiation-induced precipitates, i.e. probabiy carbides; was concluded as a working hypothesis. Several results of complementary experimental and theoretical studies were cited and seem to support this idea.

Like in Russian type VVER RPV stee?s, no indication of void formation in western type RPV steels due to irradiation at the working temperature of pressurized water reactors could be found from PAS techniques $/ 7-10 \%$. It has been tried to interpret PAS resuits in tems of the ideas from the literature, name iy the formation of irradiation-enhanced copper.precipitates and solute coated microvoids /26, $27 /$ as well as simply in terms of dislocation density changes $/ 10 /$. A critical discussion /21, 23/ of these interpretations on western type A533B RPV steels /8, 10/ has shown that the idea of positron trapping by irradiation-induced precipitates, i.e. probably carbides, developed from the study of VVER type RPV steels, can be applied as well in this class of materials.

The interaction between particles and dislocation, ie. precipitation hardening, can a 7 ready be we:1 described and understood in two-phase systems, where the volume fraction of particles is less than $10 \%$ and the size of particles not more than a few hundred nanometer (see ref./34/ and references therein). From these considerations it becones ciear that for more compi icated systems, like RPV stee is including nanometersized particles, it will be very difficu?t to evaluate the interaction between these particles and dislocations without having very detaijed informations about the properties of the precipitates. Recently, considerations have been published regarding the mechanism of void nucleation at a $\mathrm{M}_{23} \mathrm{C}_{6} / 4 x-\mathrm{Fe}$ interface due to interfacial dislocations $/ 35 /$, which may be a base for a better linderstanding of pas data in RPV steels. The final aim of any evaluation should be the quantitative explanation of changes in the mechanical properties of RPV steels known as neutron embrittlement. On the other hand it would be good to understand the formation process of these precipitates, especially the role of copper, in more detail in order to evaluate their formation and influence as a function of the chemistry of the RPV stee?s for given irradiation conditions.

\section{References}

/ 1/ B.L. Eyre and J.R. Matthews, J. Nucl. Mat. 205 (1993) 1

; 2/ W.J. Phythian and C.A. English, J. Nuc?. Mat. 205 (1993) 162

/ 3/ J.T. Busweil, E.A. Little, R.8. Jones and R.N. Sinclair, in: Proc. Second 
International Symposium on Environmental Degradation of Materials in Nuclear Power Systems - Water Reactors, eds.: J.T.A. Roberts, J.R. Weeks and G.J. Theus, American Nuclear Sòciety, La Grange Park; 1986, p. 139

/ 4/ P.A. Beaven, F. Frisius, R. Kampmann, R. Wagner and R. Hawthorne, in: Radiation Embrittlement of Nuclear Reactor Pressure Vessel Steels: An International Review (Third Volume), ASTM STP 1011, ed.: L.E. Steele, American Society for Testing and Materials, Philadelphia, 1989, p. 243

/ 5/ G. Solt, F. Frisius, W.B. Waeber, in: Radiation Embrittlement of Nuclear Reactor Pressure Vessel Steels: An International Review (Third Volume), ASTM STP 1011, ed.: L.E. Steole, American Society for Testing and Materials, Philadelphia, 1989 , p. 229

/ 6/ G. Solt, W.B. Waeber, F. Frisius and U. Zimmermann, Mat. Sci. Forum 97-99 (1992) 273

/ 7/ K. Ghazi-Wakili, U. Zimmermann, J. Brunner, P. Tipping, W.B. Waeber and F. Heinrich, Phys. Status Solidi (a) 102 (1987) 153

/ 8/ C. LopesGi1, A.P. DeLima, N. AyresDeCampos, J.V. Fernandes, G. Köge1, P. Sperr, W. Triftshäuser and D. Pachur, J. Nucl. Mater. 161 (1989) 1

/ 9/ G.H. Dat, P. Moser and J.C. Van Duysen, Mat. Sci. Forum 105-110 (1992) 941

/10/ R. Pareja, N. DeDiego, R.M. DeLacruz and J. DelRio, Nucl. Technology 104 (1993) 52

/11/ G. Albertini, R. Coppola and F. Rustichelli, Phys. Reports 233 (1993) 137

/12/ Positrons in Solids. Topics in current physics, vo1.12. Ed.: P. Hautojärvi (Springer, Berlin, 1979)

113/ Positron Sol fd-state Physics. Proc. International School of Physics "Enrico Fermi", Course LXXXIII, Varenna on Lake Como, 1981. eds.: W. Brandt and

A. Dupaquier (North Holland, Amsterdam, 1983)

/14/ G. Dlubek, H. Krause, S. Krause, P. Lademann, Mat. Sci. Forum 105-110 (1992) 977

/15/ M.J. Puska, P. Lank 1 and R.M. Nieminen, J. Phys.: Condens. Matter 1 (1989) 6081

/16/ M. Jibaly, A. Weiss, A.R. Koymen, D. MehT, L. Stiborek and C. Lei, Phys. Rev. B44 (1991) 12166;

/17/ W. Brandt, App1. Phys. 5 (1974) 1

/18/ M.J. Puska and R.M. Nieminen,-J. Phys. F13 (1983) 333

/19/ M. Brumovsky, Report ZJE-277 (1987), Skoda P1zen

120/ K. Törrönen, Report VTT-22 (1979), Technical Research Centre of Finland

/21/ G. Brauer, L. Liszkay, B. Molnar and R. Krause, Nuc1. Eng. Des. 127 (1991) 47

/22/ M.J. Puska, M. Sob, G. Brauer and T. Korhonen, Phys. Rev. B (in press)

/23/ G. Brauer, M.J. Puska, M. Sob and T. Korhonen, submitted to Nucl. Eng. Design

/24/ P. Hautojärvi, L. Pöllänen, A. Vehanen and J. Yli-Kauppila, J. Nucl. Mater. 114 (1982) 250

/25/ A. Vehanen, P. Hautojärvi, J. Johansson, J. Yli-Kauppila and P. Moser, Phys. Rev. B25 (1982) 762

/26/ G.R. Odette, Scr. Meta17. 17 (1983) 1183

/27/ G.E. Lucas, G.R. Odette, P.M. Lombrozo and J.W. Sheckherd, in: Effects of radiation on materials: Twelfth international symposium, ASTM STP 870, eds.: F.A. Garner and J.S. Perrin, American Society for Testing and Materials, Philadelphia. 1985, p. 900

/28/ G. Brauer, W. Matz, L. Liszkay, B. Molnar and R. Krause, Mat. Sci. Forum 97-99 (1992) 379

/29/ G. Brauer, F. Eichhorn, F. Frisius and R. Kampmann, in: Effects of Radiation on Mațerials: 16th International Symposium, ASTM STP 1175, eds.: A.S. Kumar, D.S. Gelles, R.K. Nanstad and E.A. Little, American Society for Testing and Materials, Philadelphia, 1994, p. 503

/30/ G. Brauer and F. Eichhorn, Nucl. Eng. Des. 143 (1993) 301

/31/ M. GroBe, J. Böhmert and H. $-W$. Viehrig, submitted to J. Nucl. Mater.

/32/ M.K. Miller, R. Jayaram, P.J. Othen and G. Brauer, at: Sixth International Symposium on Environmental Degradation of Materials in Nuclear Power Systems Water Reactors, San Diego, August 1-5, 1993

/33/ M. GroRe, F. Eichhorn, J. Böhmert, G. Brauer, H.-G. Haubold and G. Goerigk, to be presented at: EUROMAT 94, Balatonföldvar, May 30 - June 1, 1994

/34/ V. Gerold, Precipitation hardening, in: Dislocations in solids, vol.4. Ed.: F.R.N. Nabarro (North Holland, Amsterdam, 1979) p.219

/35/ B.A. Sentor, Philos. Mag. A54 (1986) 851 